\title{
Kinematic versus mechanical alignment for primary total knee arthroplasty with minimum 2 years follow-up: a systematic review
}

\author{
Elliot Sappey-Marinier ${ }^{1, *}$, Adrien Pauvert ${ }^{1}$, Cécile Batailler ${ }^{1}$, John Swan ${ }^{1}$, Laurence Cheze ${ }^{2}$, \\ Elvire Servien $^{1,3}$, and Sébastien Lustig ${ }^{1,2}$ \\ ${ }^{1}$ FIFA medical center of excellence, Orthopaedics Surgery and Sports Medicine Department, Croix-Rousse Hospital, Hospices Civils de \\ Lyon, 103 Grande rue de la Croix Rousse, 69004 Lyon, France \\ 2 Univ Lyon, Claude Bernard Lyon 1 University, IFSTTAR, LBMC UMR_T9406, 69622 Lyon, France \\ 3 LIBM - EA 7424, Interuniversity Laboratory of Biology of Mobility, Claude Bernard Lyon 1 University, 69100 Villeurbanne, France
}

Received 23 April 2020, Accepted 24 April 2020, Published online 17 June 2020

\begin{abstract}
Purpose: The aim of this study was to perform a systematic review of the literature to determine whether there are any clinical or radiological differences in mechanically aligned Total Knee Arthroplasty (TKA) compared with kinematically aligned TKA. Methods: This study included retrospective cohort studies, prospective randomized controlled trials (PRCTs) and prospective cohort studies comparing clinical and radiological outcomes, and complications in TKA with kinematic alignment (KA) and mechanical alignment (MA). All studies had a minimum follow-up of 2 years. Results: Five PRCTs published between 2014 and 2020 were included. These studies showed a low risk of bias and were of very high quality. We did not find a superiority of KA compared to MA technique for clinical and radiological outcomes, except in one study which showed a significant difference favoring KA between the two groups for all clinical scores. Conclusion: We found that KA in TKA achieved clinical and radiological results similar to those of MA. The complication rate was not increased for KA TKAs. Studies with longer follow-up and larger cohorts are required to prove any benefit of KA technique over MA technique.
\end{abstract}

Key words: Total knee arthroplasty, Total knee replacement, Mechanical alignment, Kinematic alignment, Systematic review.

\section{Introduction}

Total knee arthroplasty (TKA) is an effective method for the treatment of severe osteoarthritis of the knee [1]. One of the foundations of a successful TKA is the restoration of neutral knee alignment [2]. Mechanical alignment (MA) in TKA aims to position both femoral and tibial components perpendicular to the mechanical axis of each bone. This allows to obtain a hipknee-ankle (HKA) angle of the limb of $180^{\circ}$ considered as neutral under static weightbearing conditions [3]. This is a fundamental principle of TKA, willing to obtain a symmetric balanced load distribution between the medial and lateral compartments in order to minimize wear and potential component loosening [4-8].

However, this situation differs from the native knee. Indeed, the tibial coronal alignment averages $3^{\circ}$ varus and the mean

\footnotetext{
*Corresponding author: esappey@gmail.com
}

femoral coronal alignment is of $3^{\circ}$ valgus relative to the mechanical axis. Moreover, there is a wide individual variation in limb alignment. Bellemans et al. showed that more than 30\% of male non-arthritic patients had a constitutional varus angle of $>3^{\circ}$ [9]. Also, Hirschmann et al. showed a wide distribution of femoral and tibial coronal alignment in young non-osteoarthritic knees [10]. If such patients undergo TKA according to MA principles, medial or lateral soft tissue adjustments may be required [9, 11, 12], which could explain the results of various studies $[13,14]$ showing that up to $20 \%$ of patients are dissatisfied after TKA.

Therefore, kinematic alignment (KA) for TKA, in the wider sense, has been proposed as an alternative approach to neutral mechanical alignment [15]. This alternative alignment approach is more patient-specific and is defined by four alignment strategies: anatomic alignment, adjusted mechanical alignment, kinematic alignment, and restricted alignment techniques [16]. In different studies assessing this alternative alignment, there still 
persists some ambiguities on which of the four techniques was analyzed, while all authors name it kinematic alignment in the wider sense. KA aims to position TKA implants to match the native anatomy of each patient. It produces anatomic rather than systematic component positions, more physiological joint line obliquity and more physiological knee kinematics [17]. Defenders of KA suggest that this will improve clinical results in terms of pain and function compared to MA technique by reducing the need for ligament releases and improve soft tissue balancing [18-20]. However, there are concerns on implant survival with implants positioned in a different way from traditional targets [5, 21-23]. Several systematic reviews were performed comparing KA and MA techniques at an early follow-up [2, 24-29]. No review has been performed comparing KA and MA with a minimum follow-up of 2 years. Thus, the aim of this study was to perform a systematic review of the literature to determine whether there are any clinical or radiological differences in mechanically aligned TKA compared with kinematically aligned TKA. Our outcome variables included clinical rating scores, radiological outcomes, survivorship, complications or gait analysis at a minimum follow-up of 2 years.

\section{Methods}

\section{Literature search strategy}

For this study, the Preferred Reporting Items for Systematic Reviews and Meta-Analyses (PRISMA) guidelines were followed [30]. A first electronic search was performed using PubMed, Ovid Medline and Cochrane library from their dates of inception to the 2nd March 2020. To maximize sensitivity of the search strategy the authors combined the terms "knee", "arthroplasty", "replacement", "kinematic", "kinematically", "mechanical", "mechanically", and "alignment" when searching in the title, abstract, keywords, and MeSH fields. A secondary search was performed examining the references cited in the articles found in the primary search. All articles were reviewed by two authors independently following this systematic approach. Each reviewer was blinded with regard to the determination of the other reviewer. Ethical approval was not necessary in this study as it only analyzed current studies and did not collect individual patient data. No external funding was received for this project.

\section{Selection criteria}

This study included retrospective cohort studies, prospective randomized controlled trials (PRCTs), and prospective cohort studies comparing clinical and radiological outcomes with KA and MA in TKA. For inclusion, studies contained a KA group and a MA group with a minimum of 10 TKAs in each group and a minimum follow-up of 2 years. Final analysis involved studies reporting clinical outcome scores, survivorship, complications, or postoperative radiographic alignment between kinematic and mechanical alignment prostheses. When several studies reported the results of the same patient series with different follow-ups, only the last study with the longest follow-up was analyzed. All publications included were limited to those written in English language, involving human subjects, and full-text availability for the articles. Case reports, duplicate studies, letters, noncomparative studies, conference presentations, expert opinions, and reviews were excluded.

\section{Data extraction}

All the relevant data were extracted from article text, figures, and tables. Two investigators independently reviewed and extracted data from the retrieved articles. Discrepancies at the full-text stage were resolved by consensus between the two reviewers. If a consensus could not be reached, a third, more senior reviewer helped to resolve the discrepancy. The two reviewers collected information regarding the authors, publication origin, publication date, patient demographics (age, gender, sample size, and body mass index (BMI)), surgical methods, prosthetic designs, and outcome measurements.

The primary outcomes were the clinical and radiological results. The clinical results included the Knee Society score (KSS) [31], Western Ontario and McMaster Universities Osteoarthritis Index (WOMAC) [32], Oxford Knee score (OKS) [33], range of motion (ROM), Hospital for special surgery (HSS) score, Forgotten Joint Score (FJS) [34], Knee Injury and Osteoarthritis Outcome Score (KOOS JR) [35], a visual analog score for satisfaction, and the University of California Los Angeles (UCLA) Activity Score [36].

\section{Quality assessment}

A risk-of-bias evaluation was performed using the Cochrane Collaboration tool [37]. Seven domain-based evaluations related to risk of bias were performed, including evaluation for random sequence generation (selection bias), allocation concealment (selection bias), blinding of the participants and personnel (performance bias), blinding of the assessors (defection bias), incomplete outcome data (attrition bias), and selective reporting (reporting bias) and other biases. The overall quality of each study was evaluated as a "low risk of bias", a "high risk of bias", or an "unclear risk of bias".

A modified Jadad score was used for the quality evaluation of PRCTS including data analysis, blinding, randomization, withdrawal, adverse reactions, and inclusion criteria. Low-quality studies scored from 0 to 3 and high-quality studies scored from 4 to 8 .

\section{Statistical analysis}

Descriptive statistics, such as means, ranges, and measures of variance (standard deviations, 95\% confidence intervals (CI)), are presented where applicable. No meta-analysis was performed.

\section{Results}

The selection procedure is shown in Figure 1. A total of 1156 studies were identified by using our primary and 


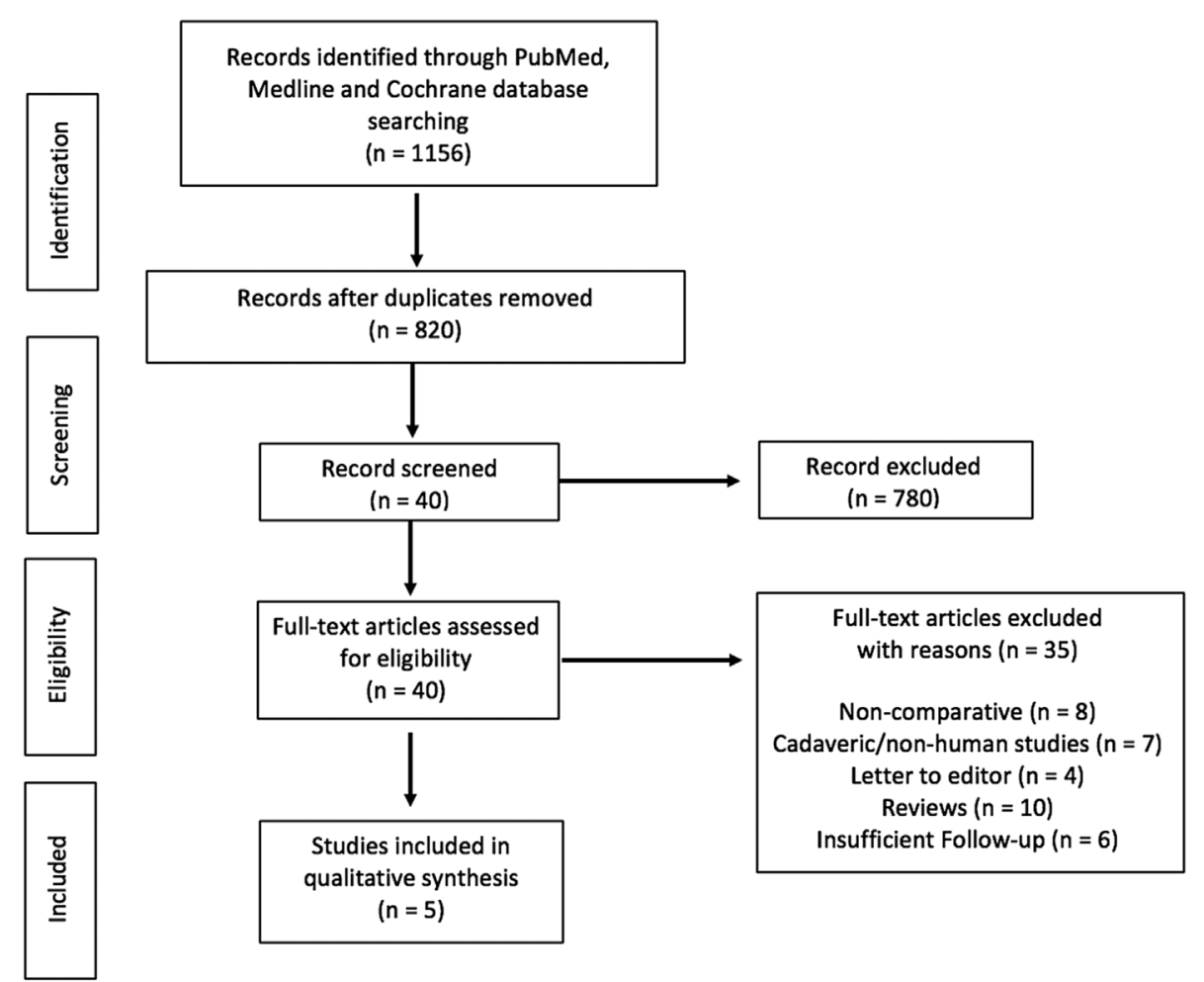

Figure 1. Flow chart.

secondary search strategy. After exclusion of duplicate studies, a total of 820 studies remained for further screening. Examination of title/abstracts excluded 780 records, and a further 35 were excluded. Thus, 5 PRCTs were included [18, 38-41] and were published between 2014 and 2020. Characteristics of the studies included are reported in Table 1.

\section{Risk of bias and quality of evidence}

Risk-of-bias assessment results of the studies are reported in Figure 2. There was an unclear risk of bias in one study in blinding the outcome assessment (detection bias). There was an unclear risk of bias for the category "other bias" in three studies. We did not find other bias in the included studies. The quality evaluation scores of the studies are shown in Table 2. The studies included in this systematic review were given scores of 8 . Thus, after examination, the five included studies had a low risk of bias and were of very high quality.

\section{Clinical results}

Four studies did not find any significant difference between the two groups (mechanical or kinematic alignment) for all the scores [38-41]. One study found a significant difference between the two groups for all the scores [18]. In this study, patients who underwent kinematically aligned TKA had significantly better scores for pain, function, and ROM than those who underwent mechanically aligned TKR. Patients in
KA group had less pain according to the OKS and WOMAC scores. The mean flexion was increased by $8.5^{\circ}$ in the KA group compared to the MA group. All clinical results are reported in Table 3.

\section{Radiological results}

For all studies, postoperative HKA was not significantly different between both groups. However, in each study, the tibial component was placed significantly more in varus (from $2^{\circ}$ to $3.5^{\circ}$ ) in the KA group compared to the MA group. Also, four studies reported the femoral component positioning and it was significantly more in valgus (from $1.3^{\circ}$ to $1.8^{\circ}$ ) in the KA group compared to the MA group. All radiographic results are reported in Table 4.

\section{Other measurements}

Among studies, three reported postoperative complication rate between MA and KA groups at the last follow-up and no significant difference was found [18, 38, 41]. One study compared gait analysis, and no significant difference was found between the KA and MA groups [39]. Laende et al. [40] compared the tibial component migration at two years which was not significantly different between both groups. McEwen et al. [41] in their study found that significantly more patients preferred their KA joint and patients were visually insensitive to HKA angle asymmetry. 
Table 1. Characteristic of the studies.

\begin{tabular}{|c|c|c|c|c|c|c|c|c|c|c|c|c|c|c|c|c|}
\hline \multirow[t]{2}{*}{ Studies } & \multirow[t]{2}{*}{ Location } & \multirow[t]{2}{*}{$\begin{array}{l}\text { Study } \\
\text { design }\end{array}$} & \multirow[t]{2}{*}{$\begin{array}{c}\text { Minimum } \\
\text { follow-up (m) }\end{array}$} & \multicolumn{2}{|c|}{$\begin{array}{c}\text { Sample } \\
\text { size } \\
\end{array}$} & \multicolumn{2}{|c|}{$\begin{array}{c}\text { Me an } \\
\text { age }\end{array}$} & \multicolumn{2}{|c|}{ Female } & \multicolumn{2}{|c|}{$\begin{array}{c}\text { BMI } \\
\text { (mean) }\end{array}$} & \multirow[t]{2}{*}{$\begin{array}{l}\text { Prosthesis } \\
\text { design }\end{array}$} & \multirow[t]{2}{*}{$\begin{array}{l}\text { Operative } \\
\text { method }\end{array}$} & \multirow[t]{2}{*}{$\begin{array}{c}\text { Clinic al } \\
\text { measurements }\end{array}$} & \multirow[t]{2}{*}{$\begin{array}{l}\text { Radiological } \\
\text { measurements }\end{array}$} & \multirow[t]{2}{*}{$\begin{array}{c}\text { Other } \\
\text { measurements }\end{array}$} \\
\hline & & & & KA & MA & KA & MA & KA & MA & KA & MA & & & & & \\
\hline $\begin{array}{l}\text { Dossett } \\
\quad \text { et al. [18] }\end{array}$ & United States & PRCT & 24 & 44 & 44 & 66 & 66 & 41 & 38 & 29 & 32 & $\begin{array}{l}\text { KA: Vanguard, CR, FB, } \\
\text { SR, cemented, all PR } \\
\text { MA: Vanguard, CR, FB, } \\
\text { SR, cemented, all PR }\end{array}$ & $\begin{array}{l}\text { KA: PSI } \\
\text { MA: Conventional }\end{array}$ & $\begin{array}{l}\text { OKS, WOMAC, KSS, } \\
\text { ROM }\end{array}$ & $\begin{array}{l}\text { HKA, AKA, JLOA, } \\
\text { FMA, TMA }\end{array}$ & Complications \\
\hline $\begin{array}{l}\text { Yeo } \\
\text { et al. [ 39] }\end{array}$ & South Korea & PRCT & 96 & 30 & 30 & 72 & 74 & 27 & 25 & 27 & 26 & $\begin{array}{l}\text { KA: NexGen, CR, FB, MR, } \\
\text { cemented, partial PR } \\
\text { MA: NexGen, CR, FB, } \\
\text { MR, cemented, partial } \\
\text { PR }\end{array}$ & $\begin{array}{l}\text { KA: ROBDOC system, } \\
\text { robotic aassisted } \\
\text { MA: Robotic aassisted }\end{array}$ & $\begin{array}{l}\text { HSS, WOMAC, KSS, } \\
\text { ROM }\end{array}$ & $\begin{array}{l}\text { HKA, FMA, TMA, } \\
\text { TS }\end{array}$ & Gait analysis \\
\hline $\begin{array}{l}\text { Laende } \\
\quad \text { et al. [40] }\end{array}$ & Canada & PRCT & 24 & 24 & 23 & 64 & 63 & 16 & 17 & 36 & 34 & $\begin{array}{l}\text { KA: Triathlon, CR, FB, SR, } \\
\text { cemented, all PR } \\
\text { MA: Triathlon, CR, FB, } \\
\text { SR, cemented, all PR }\end{array}$ & $\begin{array}{l}\text { KA: PSI } \\
\text { MA: Computer } \\
\text { navigation }\end{array}$ & OKS, satisfaction, UCLA & HKA, MPTA & Tibial migration \\
\hline $\begin{array}{l}\text { McEwen } \\
\quad \text { et al. [41] }\end{array}$ & Australia & PRCT & 24 & 41 & 41 & & 65 & NA & & & 31 & $\begin{array}{l}\text { KA: Triathlon, CR, FB, SR, } \\
\text { cementless femur, } \\
\text { cemented tibia, partial } \\
\text { PR } \\
\text { MA: Triathlon, CR, FB, } \\
\text { SR, cementless femur, } \\
\text { cemented tibia, partial } \\
\text { PR }\end{array}$ & $\begin{array}{l}\text { KA: computer } \\
\text { navigation } \\
\text { MA: computer } \\
\text { navigation }\end{array}$ & $\begin{array}{l}\text { OKS, FJS, KOOS, JR, } \\
\text { ROM }\end{array}$ & $\begin{array}{l}\text { HKA, FMA, TMA, } \\
\text { TS, JLOA, JLCA, } \\
\text { PTA }\end{array}$ & $\begin{array}{l}\text { Intraoperative gap laxity, } \\
\text { soft tissue release, } 4 \\
\text { specific clinical } \\
\text { questions, } \\
\text { complications }\end{array}$ \\
\hline $\begin{array}{l}\text { Young } \\
\text { et al. [38] }\end{array}$ & New Zealand & PRCT & 60 & 47 & 48 & 72 & 70 & 25 & 26 & 30 & 31.5 & $\begin{array}{l}\text { KA: Triathlon, CR, FB, SR, } \\
\text { cemented, partial PR } \\
\text { MA: Triathlon, CR, FB, } \\
\text { SR, cemented, partial } \\
\text { PR }\end{array}$ & $\begin{array}{l}\text { KA: PSI } \\
\text { MA: Computer } \\
\text { navigation }\end{array}$ & $\begin{array}{l}\text { OKS, WOMAC, FJS, } \\
\text { KSS, VAS }\end{array}$ & $\begin{array}{l}\text { HKA, FMA, TMA, } \\
\quad \text { TS }\end{array}$ & $\begin{array}{l}\text { Intraoperative gap laxity, } \\
\text { soft tissue release, } \\
\text { complications }\end{array}$ \\
\hline
\end{tabular}

NA: Not Applicable, PRCT: Prospective Randomized Controlled Trial, KA: Kinematic Alignment, MA: Mechanical Alignment, CR: Cruciate-Retaining, FB: Fixed-Bearing, SR: Single Radius, MR: Multi-Radius, PR: Patella Resurfacing, PSI: Patient-Specific Instrument, OKS: Oxford Knee Score, WOMAC: Western Ontario and McMaster Universities Osteoarthritis Index, KSS: Knee Society Score, ROM: Range of Motion, FJS: Forgotten Joint Score, VAS: Visual Analogue Scale, HSS: Hospital for Special Surgery knee score, UCLA: University of California at Los Angeles Loneliness score, KOOS JR: Knee Injury and Osteoarthritis Outcome Score Junior, HKA: Hip-Knee-Ankle angle, AKA: Anatomic Knee Angle, JLOA: Joint Line Orientation Angle, FMA: Femoral component relative to Mechanical Axis, TMA: Tibial component relative to Mechanical Axis, TS: Tibial Slope, MPTA: Medial Proximal Tibial Angle, JLCA: Joint Line Convergence Angle, PTA: Patellar Tilt Angle. 


\section{Risk of bias graph}

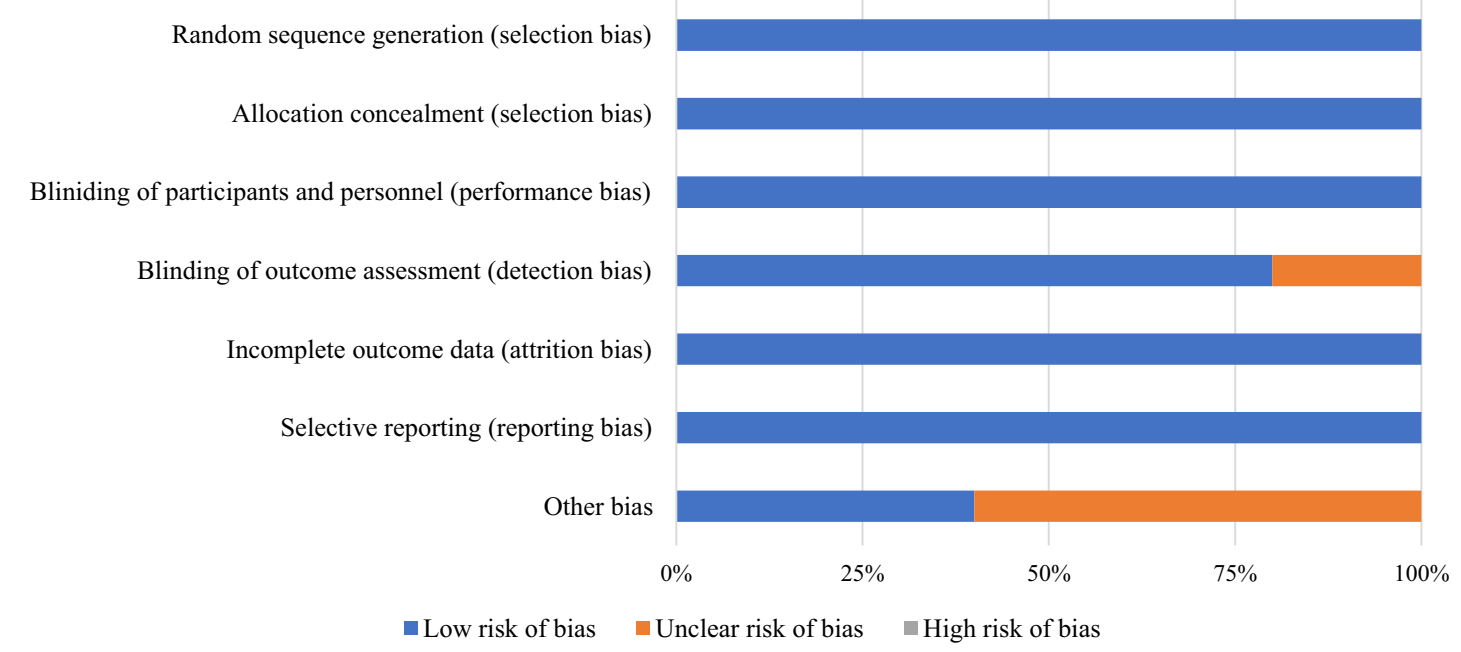

\begin{tabular}{|c|c|c|c|c|c|}
\hline & $\begin{array}{c}\text { Dossett } \\
2014\end{array}$ & $\begin{array}{c}\text { Yeo } \\
2018 \\
\end{array}$ & $\begin{array}{c}\text { Laende } \\
2019\end{array}$ & $\begin{array}{c}\text { McEwen } \\
2020\end{array}$ & $\begin{array}{c}\text { Young } \\
2020\end{array}$ \\
\hline Random sequence generation (selection bias) & + & + & + & + & + \\
\hline Allocation concealment (selection bias) & + & + & + & + & + \\
\hline Blinding of participants and personnel (performance bias) & + & + & + & + & + \\
\hline Blinding of outcome assessment (detection bias) & $?$ & + & + & + & + \\
\hline Incomplete outcome data (attrition bias) & + & + & + & + & + \\
\hline Selective reporting (reporting bias) & + & + & + & + & + \\
\hline Other bias & $?$ & $?$ & + & $?$ & + \\
\hline
\end{tabular}

Figure 2. Risk of bias graph; "+ or plus" indicates a low risk of bias; "- or minus" indicates a high risk of bias; and "? or question mark" indicates unclear of unknown risk of bias.

Table 2. Modified-Jadad score.

\begin{tabular}{|c|c|c|c|c|c|}
\hline & $\begin{array}{c}\text { Dossett et al. } \\
{[18]}\end{array}$ & $\begin{array}{l}\text { Yeo et al. } \\
\text { [ 39] }\end{array}$ & $\begin{array}{c}\text { Laende et al. } \\
{[40]}\end{array}$ & $\begin{array}{l}\text { McEwen et al. } \\
{[41]}\end{array}$ & $\begin{array}{c}\text { Young et al. } \\
{[38]}\end{array}$ \\
\hline Was the study described as randomized? & Yes & Yes & Yes & Yes & Yes \\
\hline Was the method of randomization appropriate? & Yes & Yes & Yes & Yes & Yes \\
\hline Was the study described as blinded? & Yes & Yes & Yes & Yes & Yes \\
\hline Was the method of blinding appropriate? & Yes & Yes & Yes & Yes & Yes \\
\hline Was there a description of withdrawals or dropouts? & Yes & Yes & Yes & Yes & Yes \\
\hline $\begin{array}{l}\text { Was there a clear description of the inclusion/exclusion } \\
\text { criteria? }\end{array}$ & Yes & Yes & Yes & Yes & Yes \\
\hline Was the method used to assess adverse effects described? & Yes & Yes & Yes & Yes & Yes \\
\hline Was the method of statistical analysis described? & Yes & Yes & Yes & Yes & Yes \\
\hline Total score & 8 & 8 & 8 & 8 & 8 \\
\hline
\end{tabular}

Two studies [38, 41] reported intraoperative gap laxity values and soft tissue releases. Both studies showed the same results with no significant difference being found for the gap laxity values between KA and MA groups. However, a significant increase in the number of releases was necessary to produce the target laxity values in the MA group compared to the KA group in both studies.

\section{Discussion}

This review is the first to isolate all comparative studies between KA and MA groups with a minimum follow-up of 2 years. All studies included were level I and therefore of very high quality. The most important findings of this review were to show comparable or superior clinical outcomes of KA TKA to 
Table 3. Clinical results at the last follow up ( $S D=$ standard deviation).

\begin{tabular}{|c|c|c|c|c|}
\hline \multirow[t]{2}{*}{ Studies } & \multirow[t]{2}{*}{ Clinical assessment } & \multirow{2}{*}{$\begin{array}{c}\text { Kinematic alignment } \\
\text { Mean (SD) (range) }\end{array}$} & \multirow{2}{*}{$\frac{\text { Mechanical alignment }}{\text { Mean (SD) (range) }}$} & \multirow[t]{2}{*}{$p$-value } \\
\hline & & & & \\
\hline Dossett et al. [18] & $\begin{array}{l}\text { OKS } \\
\text { WOMAC } \\
\text { KSS } \\
\text { Flexion }\end{array}$ & $\begin{array}{c}40(10.2)(15 \text { to } 48) \\
81(20.3)(33 \text { to } 100) \\
160(31.9)(93 \text { to } 200) \\
121(10.4)(100 \text { to } 150)\end{array}$ & $\begin{array}{c}33(11.1)(13 \text { to } 48) \\
70(22.6)(23 \text { to } 100) \\
137(37.9) 64 \text { to } 200) \\
113(12.5)(80 \text { to } 130)\end{array}$ & $\begin{array}{l}0.005 \\
0.005 \\
0.005 \\
0.002\end{array}$ \\
\hline Yeo et al. [39] & $\begin{array}{l}\text { HSS } \\
\text { WOMAC } \\
\text { KSS } \\
\text { Flexion }\end{array}$ & $\begin{array}{c}94.8(5.5) \\
79.6(1.8) \\
140.2(16.6) \\
129(11.5)\end{array}$ & $\begin{array}{c}93.2(8.0) \\
80.7(1.9) \\
137.6(16.1) \\
125(11.5)\end{array}$ & $\begin{array}{l}>0.05 \\
>0.05 \\
>0.05 \\
>0.05\end{array}$ \\
\hline Laende et al. [40] & $\begin{array}{l}\text { OKS } \\
\text { Satisfaction } \\
\text { UCLA }\end{array}$ & $\begin{array}{l}31(7.8) \\
94(12.9) \\
6.1(1.9)\end{array}$ & $\begin{array}{c}30(8.6) \\
91(19.0) \\
5.9(2.0)\end{array}$ & $\begin{array}{l}0.61 \\
0.49 \\
0.60\end{array}$ \\
\hline McEwen et al. [41] & $\begin{array}{l}\text { OKS } \\
\text { KOOS JR } \\
\text { FJS } \\
\text { Flexion }\end{array}$ & $\begin{array}{c}44.4(4.3)(30 \text { to } 48) \\
89.6(12.9)(55 \text { to } 100) \\
79.9(23.5)(0 \text { to } 100) \\
127(10)(101 \text { to } 154)\end{array}$ & $\begin{array}{c}44.1(4.1)(32 \text { to } 48) \\
88.5(13.7)(45 \text { to } 100) \\
79.6(19.4)(19 \text { to } 100) \\
127(11)(105 \text { to } 150)\end{array}$ & $\begin{array}{l}0.58 \\
0.69 \\
0.54 \\
0.98\end{array}$ \\
\hline Young et al. [38] & $\begin{array}{l}\text { OKS } \\
\text { WOMAC } \\
\text { FJS } \\
\text { KSS } \\
\text { VAS }\end{array}$ & $\begin{array}{c}41.4(7.2) \\
86.1(15.5) \\
68(28.8) \\
155.6(30.6) \\
78.2(16.5)\end{array}$ & $\begin{array}{c}41.7(6.3) \\
89.1(15.3) \\
74.4(23.6) \\
160.9(25.8) \\
78.4(17.1)\end{array}$ & $\begin{array}{l}0.99 \\
0.65 \\
0.29 \\
0.65 \\
0.99 \\
\end{array}$ \\
\hline
\end{tabular}

OKS: Oxford Knee Score, WOMAC: Western Ontario and McMaster Universities Osteoarthritis Index, KSS: Knee Society Score, ROM: Range of Motion, FJS: Forgotten Joint Score, VAS: Visual Analogue Scale, HSS: Hospital for Special Surgery knee score, UCLA: University of California at Los Angeles Loneliness score, KOOS JR: Knee Injury and Osteoarthritis Outcome Score Junior.

Table 4. Radiological results at the last follow up ( $S D=$ standard deviation).

\begin{tabular}{|c|c|c|c|c|}
\hline \multirow[t]{2}{*}{ Studies } & \multirow[t]{2}{*}{ Radiological assessment } & \multirow{2}{*}{$\begin{array}{c}\text { Kinematic alignment } \\
\text { Mean }(S D) \text { (range) } \\
\end{array}$} & \multirow{2}{*}{$\begin{array}{c}\text { Mechanical alignment } \\
\text { Mean }(S D) \text { (range) }\end{array}$} & \multirow[t]{2}{*}{$p$-value } \\
\hline & & & & \\
\hline Dossett et al. [18] & $\begin{array}{l}\text { HKA } \\
\text { AKA } \\
\text { JLOA } \\
\text { FMA } \\
\text { TMA }\end{array}$ & $\begin{array}{c}-0.1(2.8)(-8.5 \text { to } 7.7) \\
3.5(2.3)(0.1 \text { to } 9.5) \\
2.0(2.0)(-3.1 \text { to } 6.6) \\
1.3(2.0)(-2.4 \text { to } 6.5) \\
-2.2(2.6)(-8.7 \text { to } 4.4)\end{array}$ & $\begin{array}{c}0.1(2.5)(-4.9 \text { to } 8.9) \\
2.9(2.3)(-1.2 \text { to } 8.0) \\
0.1(2.7)(-4.1 \text { to } 8.4) \\
-0.8(2.7)(-5.8 \text { to } 6.3) \\
0.0(2.1)(-6.4 \text { to } 3.8)\end{array}$ & $\begin{array}{c}0.818 \\
0.233 \\
<0.001 \\
<0.001 \\
<0.001\end{array}$ \\
\hline Yeo et al. [39] & $\begin{array}{l}\text { HKA } \\
\text { FMA } \\
\text { TMA } \\
\text { TS }\end{array}$ & $\begin{array}{l}0.1(2.0) \\
1.7(1.9) \\
-2.5(1.7) \\
-7.5(2.8)\end{array}$ & $\begin{array}{c}-0.3(1.7) \\
-0.5(0.4) \\
0.1(0.4) \\
-6.4(1.0)\end{array}$ & $\begin{array}{l}\mathrm{n} . \mathrm{s} \\
0.04 \\
0.03 \\
\mathrm{n} . \mathrm{s}\end{array}$ \\
\hline Laende et al. [40] & $\begin{array}{l}\text { HKA } \\
\text { MPTA }\end{array}$ & $\begin{array}{l}-2.3(2.6) \\
-3.3(2.0)\end{array}$ & $\begin{array}{l}-2.1(2.1) \\
-0.8(1.7)\end{array}$ & $\begin{array}{c}0.75 \\
<0.001\end{array}$ \\
\hline McEwen et al. [41] & $\begin{array}{l}\text { HKA } \\
\text { FMA } \\
\text { TMA } \\
\text { TS } \\
\text { JLOA } \\
\text { JLCA } \\
\text { PTA }\end{array}$ & $\begin{array}{c}-1.0(2.4)(-6.0 \text { to } 3.9) \\
1.8(2.0)(-2.5 \text { to } 5.5) \\
-2.5(1.3)(-5.5 \text { to } 0.5) \\
3.1(1.8)(-0.5 \text { to } 7.5) \\
-0.9(2.6)(-6.4 \text { to } 4.9) \\
0.7(0.7)(0.0 \text { to } 3.3) \\
5.7(5.8)(-2.9 \text { to } 20 \text { or } 20.1)\end{array}$ & $\begin{array}{l}-0.2(2.1)(-4.5 \text { to } 5) \\
-0.1(0.6)(-1.5 \text { to } 1) \\
-0.3(0.4)(-1 \text { to } 0.5) \\
3.2(1.8)(-0.5 \text { to } 7.5) \\
0.8(2.1)(-5.2 \text { to } 5.2) \\
0.9(0.6)(0 \text { to } 2.2) \\
4.4(4.9)(-6 \text { to } 14.8)\end{array}$ & $\begin{array}{c}0.097 \\
<0.001 \\
<0.001 \\
0.713 \\
0.002 \\
0.14 \\
0.278\end{array}$ \\
\hline Young et al. [38] & $\begin{array}{l}\text { HKA } \\
\text { FMA } \\
\text { TMA } \\
\text { TS }\end{array}$ & $\begin{array}{c}-0.4(3)(-11 \text { to } 6) \\
2(2.5)(-4 \text { to } 6) \\
-3(3)(-10 \text { to } 4) \\
-4(2.5)(-10 \text { to } 2)\end{array}$ & $\begin{array}{c}-0.7(2)(-5 \text { to } 4) \\
0.5(1.6)(-3 \text { to } 4) \\
-0.7(1.8)(-6 \text { to } 2) \\
-1.3(2)(-7 \text { to } 3)\end{array}$ & $\begin{array}{c}0.6 \\
0.002 \\
<0.001 \\
<0.001\end{array}$ \\
\hline
\end{tabular}

HKA: Hip-Knee-Ankle angle, AKA: Anatomic Knee Angle, JLOA: Joint Line Orientation Angle, FMA: Femoral component relative to Mechanical Axis, TMA: Tibial component relative to Mechanical Axis, TS: Tibial Slope, MPTA: Medial Proximal Tibial Angle, JLCA: Joint Line Convergence Angle, PTA: Patellar Tilt Angle. 
those of MA TKA. The limb and knee alignment in KA TKA were similar to those of MA TKA, still the femoral component was placed slightly more in valgus and the tibial component was implanted in mild varus in KA TKA. The joint line orientation angle (JLOA) of the KA TKA was quite parallel to the floor and closer to the native knee than the JLOA of the MA TKA. Moreover, the complication rate was not increased for KA TKA.

More individualized alignment strategies in TKA, such as kinematic alignment, appears to be one of the "hot" topics in TKA procedures [42]. This is particularly interesting to surgeons convinced by the fundamental principles of mechanically aligned TKA, and yet willing to improve clinical results after TKA. Indeed, according to previous studies [19, 43], good performance of knee functional recovery is directly associated with patient satisfaction and implant survival. KA has gained extensive interest according to high encouraging patient-reported results [17, 19]. McEwen et al. [41] showed that significantly more patients preferred their KA joint compared to their MA joint. The satisfactory results reached with KA TKA could be attributable to the attempt to replicate the alignment of the pre-osteoarthritic knee [44]. A study of 214 cases with a mean follow-up of 38 months showed that no patients required revision of either component for loosening, wear, or instability, which helps support the efficiency of KA in TKA [45]. However, this study only analyzed a cohort of TKA aligned kinematically and did not compare with a control group.

There has been, and there still is a concern, that varus alignment of the tibial component might compromise clinical results and place implants at a higher risk for loosening [21, 46-48]. $\mathrm{KA}$, which increases the varus angle of the tibial implant, could result in different complications. However, focusing on implant survivorship, in contrast to the original concerns, KA TKA may not lead to an increased early rate of loosening [12, 20, 49, 50] considering short and mid-term follow-up. One explanation is that KA TKA restores the JLOA of the native knee, which is parallel to the floor when standing, thereby mitigating overload of the medial and lateral tibial compartment [49, 51]. Moreover, Howell et al. reported no significant difference in complication rate for TKA with KA compared to TKA with MA even at long term follow-up [52]. Laende et al. [40] showed a similar tibial component migration in the KA group compared to the MA group, even with a tibial component placed in varus. However, precautions must be taken when placing component in a kinematical alignment. Nedopil et al. highlighted a strategy for lowering the risk of tibial component loosening when performing KA which is to set the tibial component parallel to the flexion-extension plane (slope) and varus-valgus plane of the native joint line [53].

In KA TKA, the aim was to implant components in a personal position re-creating the anatomy of the pre-arthritic articular surface of each patient chosen. KA allowing a close match with the native patient anatomy and the soft tissue envelope of the knee potentially, it will potentially improve ligament balancing and minimize the need for soft tissue releases and decreases the bone resection [38, 41, 54, 55]. Moreover, Blakeney et al. showed that the knee kinematics of patients with kinematically aligned TKAs more closely resembled that of normal healthy controls than that of patients with mechanically aligned TKAs [56]. Thus, a return to normal gait parameters after TKA will potentially lead to improved clinical outcomes with greater patient satisfaction. Consequently, KA may be considered as a safe procedure based on our review and the literature.

Several limitations should be discussed. Firstly, we only found five relevant studies that compared KA with MA in TKA with a minimum follow-up of 2 years. Secondly, despite a minimum follow-up of 2 years, the follow-up periods were generally too short to determine long-term longevity and survival. Thirdly, the operative method and instrumentation used to achieve kinematic alignment was not identical in all the studies, ranging from the use of patient-specific instruments with custom cutting guides to computer navigation or robotic assisted instrumentation. Furthermore, the target alignment in KA groups was not well defined for each study. However, radiological alignment results in KA groups appeared to be comparable for all studies. And lastly, the sample size in each group was relatively small.

\section{Conclusion}

In conclusion, we found that KA in TKA achieved clinical and radiological results similar to those of MA. The complication rate was not increased for KA TKAs. The present review suggests that $\mathrm{KA}$ is an acceptable and alternative alignment to MA. Studies with longer follow-up and larger cohorts are required to prove any benefit of the KA technique over MA technique.

\section{Conflict of interest}

Prof. Sébastien Lustig has performed consultancy work for Medacta, Heraeus, Corin, Amplitude, Groupe Lépine, Depuy Synthes, Smith \& Nephew, Stryker. Prof. Sébastien Lustig and Prof. Elvire Servien receive institutional research support from Corin and Amplitude. Prof. Sébastien Lustig is a board member of KSSTA and Maitrise Orthopédique. The other authors declare that they have no conflicts of interest.

\section{References}

1. Carr AJ, Robertsson O, Graves S, et al. (2012) Knee replacement. Lancet Lond Engl 379, 1331-1340.

2. Schiraldi M, Bonzanini G, Chirillo D, de Tullio V (2016) Mechanical and kinematic alignment in total knee arthroplasty. Ann Transl Med 4, 130.

3. Insall J, Scott WN, Ranawat CS (1979) The total condylar knee prosthesis. A report of two hundred and twenty cases. J Bone Joint Surg Am 61, 173-180.

4. Berend ME, Ritter MA, Meding JB, et al. (2004) Tibial component failure mechanisms in total knee arthroplasty. Clin Orthop 26-34.

5. Jeffery RS, Morris RW, Denham RA (1991) Coronal alignment after total knee replacement. J Bone Joint Surg Br 73, 709-714. 
6. Lotke PA, Ecker ML (1977) Influence of positioning of prosthesis in total knee replacement. J Bone Joint Surg Am 59, 77-79.

7. Ritter MA, Faris PM, Keating EM, Meding JB (1994) Postoperative alignment of total knee replacement. Its effect on survival. Clin Orthop 153-156.

8. Tew M, Waugh W (1985) Tibiofemoral alignment and the results of knee replacement. J Bone Joint Surg Br 67, 551-556.

9. Bellemans J, Colyn W, Vandenneucker H, Victor J (2012) The Chitranjan Ranawat award: is neutral mechanical alignment normal for all patients? The concept of constitutional varus. Clin Orthop 470, 45-53.

10. Hirschmann MT, Moser LB, Amsler F, et al. (2019) Phenotyping the knee in young non-osteoarthritic knees shows a wide distribution of femoral and tibial coronal alignment. Knee Surg Sports Traumatol Arthrosc 27, 1385-1393.

11. Bellemans J (2011) Neutral mechanical alignment: a requirement for successful TKA: opposes. Orthopedics 34, e507-509.

12. Howell SM, Papadopoulos S, Kuznik KT, Hull ML (2013) Accurate alignment and high function after kinematically aligned TKA performed with generic instruments. Knee Surg Sports Traumatol Arthrosc 21, 2271-2280.

13. Bourne RB, Chesworth BM, Davis AM, et al. (2010) Patient satisfaction after total knee arthroplasty: who is satisfied and who is not? Clin Orthop 468, 57-63.

14. Baker PN, van der Meulen JH, Lewsey J, et al. (2007) The role of pain and function in determining patient satisfaction after total knee replacement. Data from the National Joint Registry for England and Wales. J Bone Joint Surg Br 89, 893-900.

15. Abdel MP, Oussedik S, Parratte S, et al. (2014) Coronal alignment in total knee replacement: historical review, contemporary analysis, and future direction. Bone Joint J 96-B, 857-862.

16. Rivière C, Iranpour F, Auvinet E, et al. (2017) Alignment options for total knee arthroplasty: A systematic review. Orthop Traumatol Surg Res 103, 1047-1056.

17. Howell SM, Kuznik K, Hull ML, Siston RA (2008) Results of an initial experience with custom-fit positioning total knee arthroplasty in a series of 48 patients. Orthopedics 31, 857-863.

18. Dossett HG, Estrada NA, Swartz GJ, et al. (2014) A randomised controlled trial of kinematically and mechanically aligned total knee replacements: two-year clinical results. Bone Joint J 96-B, 907-913.

19. Dossett HG, Swartz GJ, Estrada NA, et al. (2012) Kinematically versus mechanically aligned total knee arthroplasty. Orthopedics 35, e160-169.

20. Howell SM, Papadopoulos S, Kuznik K, et al. (2015) Does varus alignment adversely affect implant survival and function six years after kinematically aligned total knee arthroplasty? Int Orthop 39, 2117-2124.

21. Fang DM, Ritter MA, Davis KE (2009) Coronal alignment in total knee arthroplasty: just how important is it? J Arthroplasty 24, 39-43.

22. Pang H-N, Jamieson P, Teeter MG, et al. (2014) Retrieval analysis of posterior stabilized polyethylene tibial inserts and its clinical relevance. J Arthroplasty 29, 365-368.

23. Ritter MA, Davis KE, Meding JB, et al. (2011) The effect of alignment and BMI on failure of total knee replacement. J Bone Joint Surg Am 93, 1588-1596.

24. Luo Z, Zhou K, Peng L, et al. (2020) Similar results with kinematic and mechanical alignment applied in total knee arthroplasty. Knee Surg Sports Traumatol Arthrosc 28, 17361741.
25. Woon JTK, Zeng ISL, Calliess T, et al. (2018) Outcome of kinematic alignment using patient-specific instrumentation versus mechanical alignment in TKA: a meta-analysis and subgroup analysis of randomised trials. Arch Orthop Trauma Surg 138, 1293-1303.

26. Yoon J-R, Han S-B, Jee M-K, Shin Y-S (2017) Comparison of kinematic and mechanical alignment techniques in primary total knee arthroplasty: A meta-analysis. Medicine (Baltimore) 96, e8157.

27. Li Y, Wang S, Wang Y, Yang M (2018) Does kinematic alignment improve short-term functional outcomes after total knee arthroplasty compared with mechanical alignment? A systematic review and meta-analysis. J Knee Surg 31, 78-86.

28. Lee YS, Howell SM, Won Y-Y, et al. (2017) Kinematic alignment is a possible alternative to mechanical alignment in total knee arthroplasty. Knee Surg Sports Traumatol Arthrosc 25, 3467-3479.

29. Courtney PM, Lee G-C (2017) Early outcomes of kinematic alignment in primary total knee arthroplasty: a meta-analysis of the literature. J Arthroplasty 32, 2028-2032.e1.

30. Liberati A, Altman DG, Tetzlaff J, et al. (2009) The PRISMA statement for reporting systematic reviews and meta-analyses of studies that evaluate healthcare interventions: explanation and elaboration. BMJ 339, b2700.

31. Insall JN, Dorr LD, Scott RD, Scott WN (1989) Rationale of the Knee Society clinical rating system. Clin Orthop 13-14.

32. Bellamy N, Buchanan WW (1986) A preliminary evaluation of the dimensionality and clinical importance of pain and disability in osteoarthritis of the hip and knee. Clin Rheumatol 5, 231-241.

33. Dawson J, Fitzpatrick R, Murray D, Carr A (1998) Questionnaire on the perceptions of patients about total knee replacement. J Bone Joint Surg Br 80, 63-69.

34. Behrend H, Giesinger K, Giesinger JM, Kuster MS (2012) The "forgotten joint" as the ultimate goal in joint arthroplasty: validation of a new patient-reported outcome measure. J Arthroplasty 27, 430-436.e1.

35. Lyman S, Lee Y-Y, Franklin PD, et al. (2016) Validation of the KOOS, JR: a short-form knee arthroplasty outcomes survey. Clin Orthop 474, 1461-1471.

36. Zahiri CA, Schmalzried TP, Szuszczewicz ES, Amstutz HC (1998) Assessing activity in joint replacement patients. J Arthroplasty 13, 890-895.

37. Higgins JPT, Altman DG, Gøtzsche PC, et al. (2011) The Cochrane Collaboration's tool for assessing risk of bias in randomised trials. BMJ 343, d5928.

38. Young SW, Sullivan NPT, Walker ML, et al. (2020) No difference in 5-year clinical or radiographic outcomes between kinematic and mechanical alignment in TKA: a randomized controlled trial. Clin Orthop 478, 1271-1279.

39. Yeo J-H, Seon J-K, Lee D-H, Song E-K (2019) No difference in outcomes and gait analysis between mechanical and kinematic knee alignment methods using robotic total knee arthroplasty. Knee Surg Sports Traumatol Arthrosc 27, 1142-1147.

40. Laende EK, Richardson CG, Dunbar MJ (2019) A randomized controlled trial of tibial component migration with kinematic alignment using patient-specific instrumentation versus mechanical alignment using computer-assisted surgery in total knee arthroplasty. Bone Joint J 101-B, 929-940.

41. McEwen PJ, Dlaska CE, Jovanovic IA, et al. (2020) Computerassisted kinematic and mechanical axis total knee arthroplasty: a prospective randomized controlled trial of bilateral simultaneous surgery. J Arthroplasty 35, 443-450. 
42. Hirschmann MT, Karlsson J, Becker R (2018) Hot topic: alignment in total knee arthroplasty-systematic versus more individualised alignment strategies. Knee Surg Sports Traumatol Arthrosc 26, 1587-1588.

43. Rothwell AG, Hooper GJ, Hobbs A, Frampton CM (2010) An analysis of the Oxford hip and knee scores and their relationship to early joint revision in the New Zealand Joint Registry. J Bone Joint Surg Br 92, 413-418.

44. Mugnai R, Digennaro V, Ensini A, et al. (2014) Can TKA design affect the clinical outcome? Comparison between two guided-motion systems. Knee Surg Sports Traumatol Arthrosc 22, 581-589.

45. Howell SM, Howell SJ, Kuznik KT, et al. (2013) Does a kinematically aligned total knee arthroplasty restore function without failure regardless of alignment category? Clin Orthop 471, 1000-1007.

46. Bargren JH, Blaha JD, Freeman MA (1983) Alignment in total knee arthroplasty. Correlated biomechanical and clinical observations. Clin Orthop 178-183.

47. Halder A, Kutzner I, Graichen F, et al. (2012) Influence of limb alignment on mediolateral loading in total knee replacement: in vivo measurements in five patients. J Bone Joint Surg Am 94, 1023-1029.

48. Kim Y-H, Park J-W, Kim J-S, Park S-D (2014) The relationship between the survival of total knee arthroplasty and postoperative coronal, sagittal and rotational alignment of knee prosthesis. Int Orthop 38, 379-385.
49. Hutt J, Massé V, Lavigne M, Vendittoli P-A (2016) Functional joint line obliquity after kinematic total knee arthroplasty. Int Orthop 40, 29-34.

50. Nedopil AJ, Howell SM, Hull ML (2016) Does malrotation of the tibial and femoral components compromise function in kinematically aligned total knee arthroplasty? Orthop Clin North Am 47, 41-50.

51. Ji H-M, Han J, Jin DS, et al. (2016) Kinematically aligned TKA can align knee joint line to horizontal. Knee Surg Sports Traumatol Arthrosc 24, 2436-2441.

52. Howell SM, Shelton TJ, Hull ML (2018) Implant survival and function ten years after kinematically aligned total knee arthroplasty. J Arthroplasty 33, 3678-3684.

53. Nedopil AJ, Howell SM, Hull ML (2017) What mechanisms are associated with tibial component failure after kinematicallyaligned total knee arthroplasty? Int Orthop 41, 1561-1569.

54. An VVG, Twiggs J, Leie M, Fritsch BA (2019) Kinematic alignment is bone and soft tissue preserving compared to mechanical alignment in total knee arthroplasty. Knee 26, 466476.

55. Chia Z-Y, Pang H-N, Tan M-H, Yeo S-J (2018) Gap difference in navigated TKA: a measure of the imbalanced flexionextension gap. SICOT-J 4, 30.

56. Blakeney W, Clément J, Desmeules F, et al. (2019) Kinematic alignment in total knee arthroplasty better reproduces normal gait than mechanical alignment. Knee Surg Sports Traumatol Arthrosc 27, 1410-1417.

Cite this article as: Sappey-Marinier E, Pauvert A, Batailler C, Swan J, Cheze L, Servien E \& Lustig S (2020) Kinematic versus mechanical alignment for primary total knee arthroplasty with minimum 2 years follow-up: a systematic review. SICOT-J 6, 18 